\title{
PROTEÇÃO FÍSICO-MECÂNICA DA BASE DE UMA ENCOSTA NA MARGEM DO RIO URUGUAI COM ENROCAMENTO VIVO
}

\author{
Junior Joel Dewes ${ }^{1}$; Rita dos Santos Sousa ${ }^{2}$; Paula Letícia Wolff Kettenhuber; \\ Fabrício Jaques Sutili ${ }^{4}$ \\ ${ }^{1}$ Mestrando do Programa de Pós-Graduação em Engenharia Florestal da \\ Universidade Federal de Santa Maria, Santa Maria, Brasil \\ (juniordewes2011@gmail.com) \\ ${ }^{2}$ Doutoranda do Programa de Pós-Graduação em Engenharia Florestal da \\ Universidade Federal de Santa Maria, Santa Maria, Brasil \\ ${ }^{3}$ Doutoranda do Programa de Pós-Graduação em Engenharia Florestal da \\ Universidade Federal de Santa Maria, Santa Maria, Brasil \\ ${ }^{4}$ Prof. Doutor do Departamento de Ciências Florestais da Universidade Federal de \\ Santa Maria, Santa Maria, Brasil
}

Recebido em: 06/04/2018 - Aprovado em: 10/06/2018 - Publicado em: 20/06/2018 DOI: 10.18677/EnciBio_2018A71

\begin{abstract}
RESUMO
Com a ocorrência de intensos fenômenos pluviométricos, o volume de água excedente em reservatórios de usinas hidrelétricas necessita ser escoado, o que geralmente implica em vertimentos de grandes vazões que podem comprometer a estabilidade de taludes e encostas localizadas a jusante do vertedouro. Devem ser, por isso, adotadas soluções técnicas adequadas para minimizar perdas de solo e danos à flora e a fauna. Uma técnica apropriada para proteção de margens fluviais é o enrocamento vivo. O objetivo deste trabalho é descrever a execução de um enrocamento com plantas realizado em um trecho da margem esquerda do rio Uruguai a jusante da barragem da UHE Itá, desde uma breve caracterização projetual até os resultados atingidos dois anos após sua execução. $O$ acompanhamento da obra para análise qualitativa do comportamento da estrutura e do desenvolvimento das plantas foi feito regularmente. $O$ levantamento da vegetação arbustiva e arbórea foi realizado através da implantação de 6 parcelas permanentes de $10,0 \mathrm{~m}$ de comprimento e $1,7 \mathrm{~m}$ de altura $\left(17 \mathrm{~m}^{2}\right)$. A primeira campanha de medição foi realizada imediatamente após a execução da obra e a segunda após 24 meses. Os resultados obtidos confirmam que o enrocamento vivo está a cumprir de forma eficiente a proteção mecânica da base da encosta dois anos após a intervenção, sendo que nenhum dano físico foi observado na estrutura e que as plantas se encontram em pleno desenvolvimento vegetativo e estão a contribuir para o aumento da estabilidade da estrutura através de seus sistemas radiculares e parte aérea.
\end{abstract}

PALAVRAS-CHAVE: Engenharia natural; estabilidade de taludes; estabilização hidráulica.

\section{PHYSICAL-MECHANICAL PROTECTION OF A SLOPE ON THE URUGUAY RIVER BANK WITH LIVE RIP-RAP}




\begin{abstract}
With the occurrence of intense rainfall phenomena, the surplus water volume in reservoirs of hydropower plants needs to be drained, which usually implies in spillage of large stream discharge that can compromise the stability of slopes and hillsides downstream of the spillway. Appropriate technical solutions should therefore be used to minimize soil losses and damage to flora and fauna. One suitable technique for streambanks protection is the live rip-rap. The aim of this work is to describe the execution of a live rip-rap carried out in a section of the left bank of the Uruguay river downstream of the UHE Itá dam, from a brief design characterization to the results achieved two years after its execution. The monitoring of the work for qualitative analysis of the structure's behavior and the development of the plants was regularly done. Shrub and tree data were collected through the implantation of 6 permanent plots of $10,0 \mathrm{~m}$ in length and $1,7 \mathrm{~m}$ in height $\left(17 \mathrm{~m}^{2}\right)$. The first measurement campaign was carried out immediately after the execution of the work and the second after 24 months. The results obtained with this work confirm that live rip-rap is efficiently fulfilling with the mechanical protection of the slope two years after the intervention, no physical damage was observed in the structure and that vegetation is in full development and are contributing to increase stability of the structure through its root systems and canopies.
\end{abstract}

KEYWORDS: Soil bioengineering; slope stability; hydraulic stabilization.

\title{
INTRODUÇÃO
}

A bacia do alto rio Uruguai localiza-se entre os estados do Rio Grande do Sul e Santa Catarina e é caracterizada por um relevo bastante ondulado e inclinado (BRASIL, 2006), encontrando-se a maior parte dos seus rios em vales bem profundos e encaixados (JUSTUS, 1990). A inclinação do relevo, combinado com os regimes pluviométricos e o uso do solo da bacia faz com que o rio Uruguai desenvolva grandes picos de vazão e grande oscilação de seu nível de água em períodos de chuva intensa (CONSÓRCIO ITÁ, 2000), podendo causar perdas de grandes volumes de solo por meio da erosão fluvial.

Este problema pode ainda ser agravado por meio da alteração da dinâmica de vazões do rio através da construção de barragens para aproveitamento elétrico, o que é comum atualmente ao longo do perfil longitudinal do alto rio Uruguai. Em momentos de intensos fenômenos pluviométricos, o volume de água excedente nos reservatórios das usinas hidrelétricas necessita ser escoado, o que geralmente implica em vertimentos de grandes vazões. Esta situação pode comprometer a estabilidade de taludes e encostas localizadas à jusante do vertedouro, devendo-se tomar medidas técnicas adequadas para minimizar perdas de solo e danos à flora e a fauna (SOUSA et al., 2017).

Uma técnica apropriada para proteção de margens fluviais é o enrocamento vivo (SOUSA et al., 2017), também denominado rip-rap. Esta técnica consiste na combinação de material inerte (pedras) e material vivo (mudas, estacas vivas, ramos inteiros) (SOUSA; SUTILI, 2017) com o objetivo de aumentar a rugosidade hidráulica e proteger física-mecanicamente a base do talude ou encosta contra o efeito adverso do fluxo da água (STUDER; ZEH, 2014). O efetivo funcionamento desta técnica permite a estabilização hidráulica do trecho tratado e uma boa integração paisagística da obra pelo uso combinado com plantas, acarretando em benefícios ecológicos e estéticos (KETTENHUBER et al., 2017). 
A execução do enrocamento vegetado preconiza a disponibilidade de material construtivo, tanto de material inerte quanto de material vivo. Por ser uma técnica com custos de execução relativamente altos, as pedras devem ser obtidas preferencialmente no próprio local, diminuindo custos de transporte e logística. Da mesma forma, a vegetação a ser instalada dentro da estrutura deve ser autóctone, uma vez que se encontra melhor adaptada às condições de clima e solo locais, acarretando em uma maior probabilidade de sucesso da intervenção.

Este relato de caso tem o objetivo de descrever a execução de um enrocamento combinado com plantas, realizado em um trecho da margem esquerda do rio Uruguai localizado a jusante da barragem da Usina Hidrelétrica de Itá (UHE Itá), no município de Aratiba (RS), desde uma breve caracterização projetual até os resultados atingidos após dois anos de desenvolvimento da vegetação.

\section{RELATO DE CASO}

A obra foi realizada na margem esquerda do rio Uruguai imediatamente a

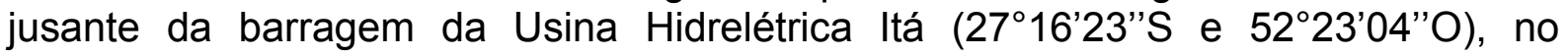
município de Aratiba, Rio Grande do Sul, Brasil. As atividades de execução do enrocamento vivo ocorreram durante o mês de dezembro de 2015 e janeiro de 2016 (verão). As dimensões da estrutura construída são de aproximadamente $400 \mathrm{~m}$ de comprimento, 1,5 m de altura e 1,0 m de largura, totalizando um volume aproximado de $375 \mathrm{~m}^{3}$ de pedra. Para a construção foram utilizadas pedras angulosas e arredondadas com tamanhos variando de $0,40 \mathrm{~m}$ a $0,70 \mathrm{~m}$ provenientes das adjacências do local da obra.

Primeiramente realizou-se o preparo da área e a melhoria da via de acesso na base da encosta com o auxílio de um trator de esteira. Na sequência realizou-se a movimentação e disposição da primeira linha de pedras com a ajuda de uma escavadeira giratória. Os espaços vazios formados entre as pedras foram preenchidos com solo oriundo do próprio local. Simultaneamente à colocação das pedras e do solo foi realizado o plantio de mudas de espécies autóctones nativas em covas entre as pedras. Para tal foram utilizadas mudas de pelo menos $0,5 \mathrm{~m}$ de altura, as quais foram colocadas em uma densidade de $3 \mathrm{un} . / \mathrm{m}^{2}$. Cada cova recebeu uma dose de $400 \mathrm{ml}$ de hidrogel e uma pequena dose de adubo orgânico e químico devidamente incorporado ao solo. Após o plantio das mudas executou-se a disposição da segunda linha de pedras e mudas, e assim sucessivamente até 1,5 m de altura. Após a execução do enrocamento vivo foram plantadas mudas arbóreas nativas com altura média de $0,5 \mathrm{~m}$ na base da estrutura. Para tal, após abertura manual das covas, incorporou-se uma pequena dose de adubo orgânico ao solo no fundo da mesma e aplicaram-se $400 \mathrm{ml}$ de hidrogel previamente ao plantio de cada muda. O espaçamento de plantio adotado foi de 1,0 m entre plantas.

Na FIGURA 1 pode-se observar de forma esquemática um trecho da estrutura em vista frontal com o seu respectivo arranjo construtivo após execução. 


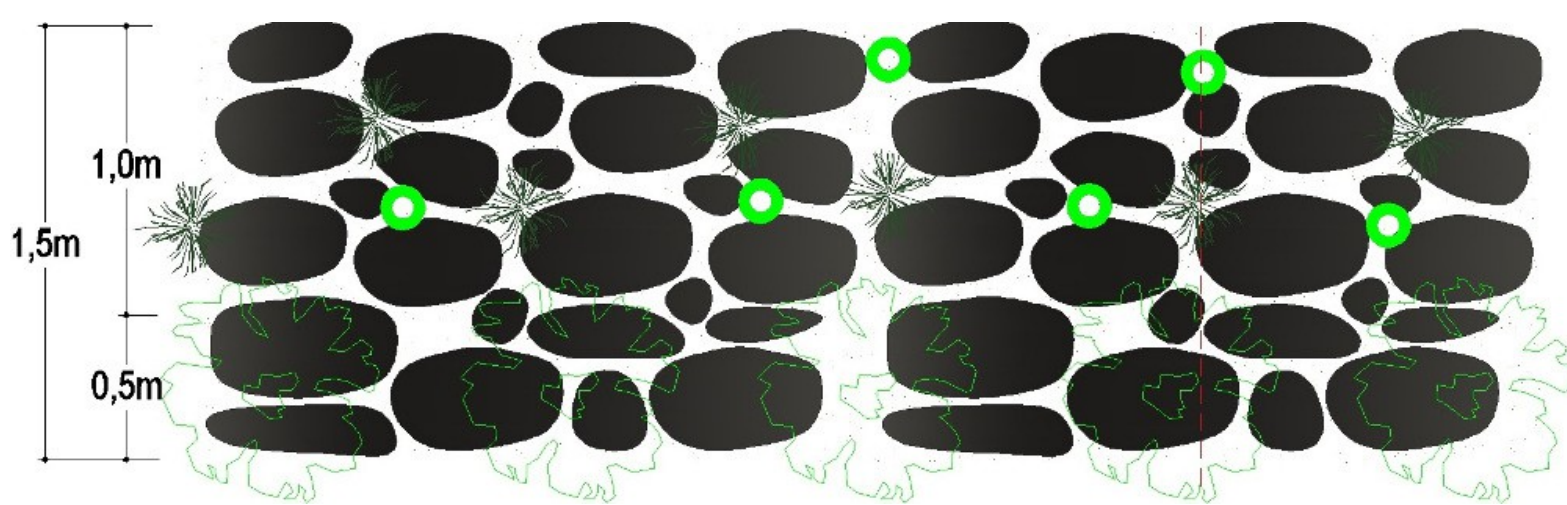

FIGURA 1 - Representação esquemática com vista frontal de um trecho de enrocamento vivo com disposição das plantas entre as pedras. Fonte: acervo pessoal.

Na FIGURA 2 pode-se observar um corte transversal e a conformação final da estrutura imediatamente após a execução.
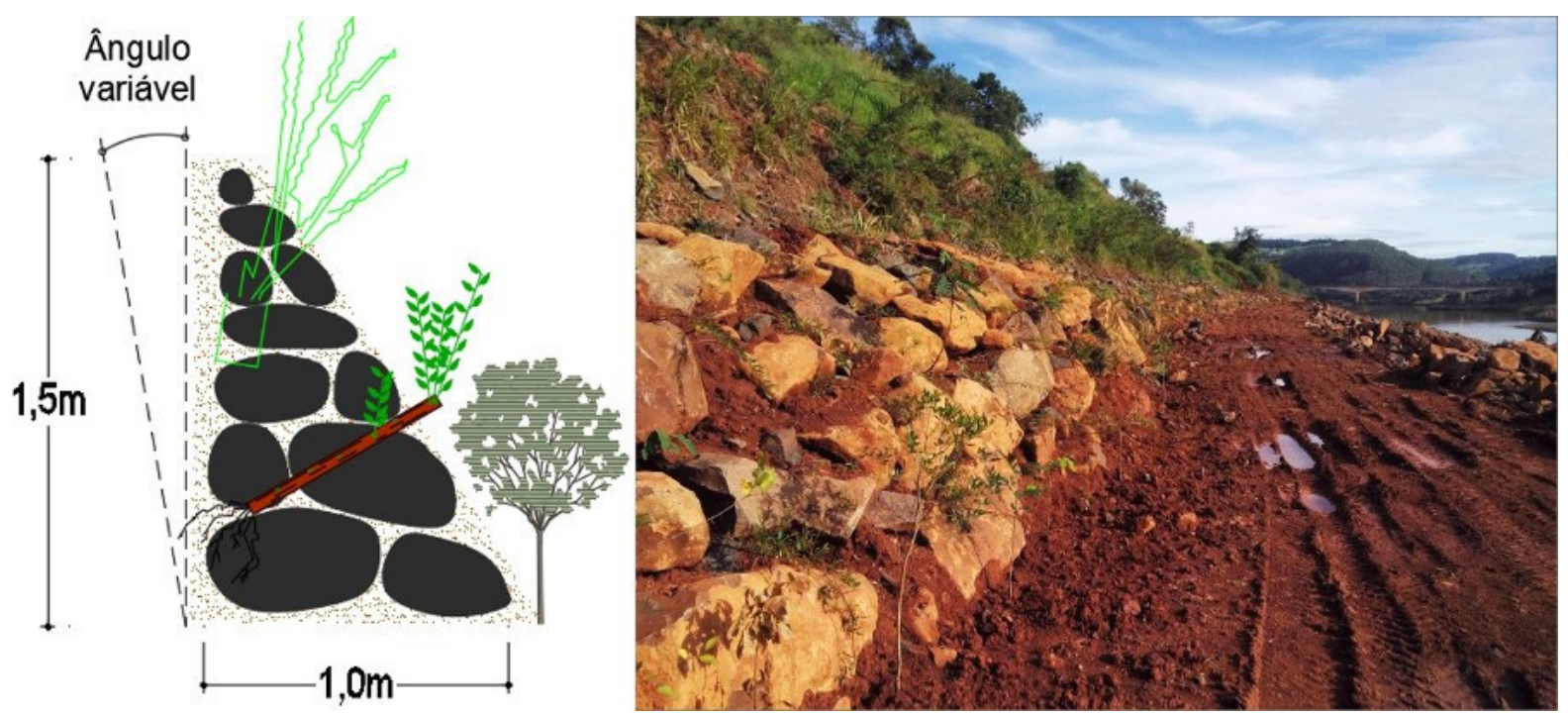

FIGURA 2 - Representação esquemática em corte transversal do enrocamento vivo com a disposição da vegetação arbustiva entre as pedras e o plantio longitudinal de espécies arbóreas na base (à esquerda). Vista longitudinal do enrocamento vivo com plantio de espécies arbustivas e arbóreas (à direita). Fonte: Rita S. Sousa (acervo pessoal).

As espécies arbustivas implantadas no enrocamento foram: Calliandra brevipes Benth., Gymnanthes schottiana Müll. Arg., Phyllanthus sellowianus (Klotzsch) Müll. Arg., Schinus terebinthifolius Raddi e Sesbania virgata (Cav.) Pers. As espécies arbóreas plantadas em linha na base do enrocamento foram: Ateleia glazioviana Baillon, Bauhinia forficata Link, Eugenia uniflora L., Inga marginata Willd., Inga vera Willd., Luehea divaricata Martius, Myrciaria tenella (DC.) O. Berg. e Sebastiania commersoniana (Baill.) L. B. Sm. \& Downs.

O acompanhamento da obra para análise qualitativa do comportamento da estrutura e do desenvolvimento das plantas foi realizado por meio de visitas regulares ao local. O levantamento da vegetação arbustiva e arbórea foi realizado através da implantação de seis parcelas permanentes de 10,0 $\mathrm{m}$ de comprimento e 
$1,7 \mathrm{~m}$ de altura $\left(17 \mathrm{~m}^{2}\right)$ distribuídas de forma equidistante ao longo da estrutura. $\mathrm{A}$ primeira campanha de medição ocorreu ao término da execução da obra e a segunda após 24 meses. Em cada ocasião foi amostrada uma área total de $102 \mathrm{~m}^{2}$, o que corresponde a $15 \%$ da área superficial total da estrutura. Foi avaliado 0 número de indivíduos de espécies arbustivas e arbóreas em cada parcela e realizado levantamento fotográfico para acompanhamento do desenvolvimento da vegetação implantada.

\section{RESULTADOS E DISCUSSÃO}

As espécies vegetais arbustivas e arbóreas plantadas no enrocamento e na base da estrutura, com as respectivas quantidades para toda a intervenção nas duas avaliações realizadas podem ser observadas na .

TABELA 1 - Relação de espécies arbustivas e arbóreas utilizadas e o número de indivíduos logo após e 24 meses após a execução do enrocamento vivo.

\begin{tabular}{|c|c|c|c|}
\hline NOME BOTÂNICO & $\begin{array}{l}\text { FAMÍLIA } \\
\text { BOTÂNICA }\end{array}$ & $\begin{array}{c}\text { QUANT. } \\
\text { (logo } \\
\text { após) }\end{array}$ & $\begin{array}{c}\text { QUANT. } \\
\text { (24 } \\
\text { meses })\end{array}$ \\
\hline \multicolumn{4}{|c|}{ Mudas arbustivas (enrocamento) } \\
\hline C. brevipes Benth. & Fabaceae & 200 & 224 \\
\hline G. schottiana Müll. Arg. & Euphorbiaceae & 1047 & 872 \\
\hline M. pigra L. & Fabaceae & - & 16 \\
\hline P. sellowianus (Klotzsch) Müll. Arg. & Phyllantaceae & 733 & 168 \\
\hline S. terebinthifolius Raddi & Anacardiaceae & 287 & 344 \\
\hline S. virgata (Cav.) Pers. & Fabaceae & 207 & 96 \\
\hline TOTAL & & 2474 & 1720 \\
\hline \multicolumn{4}{|c|}{ Mudas arbóreas (plantio em linha) } \\
\hline A. glazioviana Baillon & Fabaceae & 65 & 64 \\
\hline B. forficata Link & Fabaceae & 35 & 32 \\
\hline E. uniflora L. & Myrtaceae & 25 & 24 \\
\hline I. marginata Willd. & Fabaceae & 45 & 40 \\
\hline I. vera Willd. & Fabaceae & 25 & 24 \\
\hline L. divaricata Martius & Malvaceae & 95 & 88 \\
\hline M. tenella (DC.) O. Berg. & Myrtaceae & 25 & 24 \\
\hline S. commersoniana (Baill.) L. B. Sm. \& Downs & Euphorbiaceae & 85 & 80 \\
\hline TOTAL & & 400 & 376 \\
\hline
\end{tabular}

Conforme pode ser observado na , foram plantadas 2474 mudas de espécies arbustivas entre as pedras do enrocamento, perfazendo uma densidade de 3,6 indivíduos $/ \mathrm{m}^{2}$ de superfície da estrutura. A G. schottiana foi a espécie plantada em maior quantidade com um total de 1047 indivíduos (42\%), seguida de $P$. sellowianus com um total de 733 indivíduos (30\%) e S. terebinthifolius, com um total de 287 indivíduos (12\%). S. virgata e C. brevipes foram plantadas em menores quantidades, com 207 (8\%) e $200(8 \%)$ indivíduos, respectivamente.

No plantio linear de mudas de espécies arbóreas ao longo da base do enrocamento foram empregadas 8 espécies distintas, em um total de 400 indivíduos. As espécies com maior quantidade de mudas plantadas foram L. divaricata $(25 \%)$, S. commersoniana (21\%), A. glazioviana (16\%) e I. marginata (11\%) dos indivíduos. 
As espécies menos abundantes foram B. forficata (9\%), E. uniflora (6\%), I. vera $(6 \%)$ e M. tenella (6\%) do total de mudas.

$\mathrm{Na}$ escolha das espécies, tanto a serem implantadas no enrocamento quanto na sua base, optou-se por um grande número de espécies pertencentes à família Fabaceae (leguminosas), com o objetivo de acelerar a recuperação das condições químicas do solo por meio da fixação de nitrogênio. A quantidade de plantas pertencentes à família Fabaceae no momento da implantação foi de $20 \%$ do número total de indivíduos. Após dois anos de avaliação, esta proporção aumentou para $24 \%$.

Na mesma ocasião, a espécie encontrada com maior abundância no local da obra foi Gymnanhtes schottiana (51\%), seguida de S. terebinthifolius (20\%), C. tweedii (13\%), S. virgata (5\%) e Mimosa pigra L. (1\%). Esta última espécie colonizou espontaneamente a obra por meio de regeneração natural, atestando a sua boa capacidade em colonizar áreas anteriormente alteradas.

As percentagens de cada espécie em relação ao número total de mudas logo após e 24 meses após a execução da obra podem ser observadas na FIGURA 3.
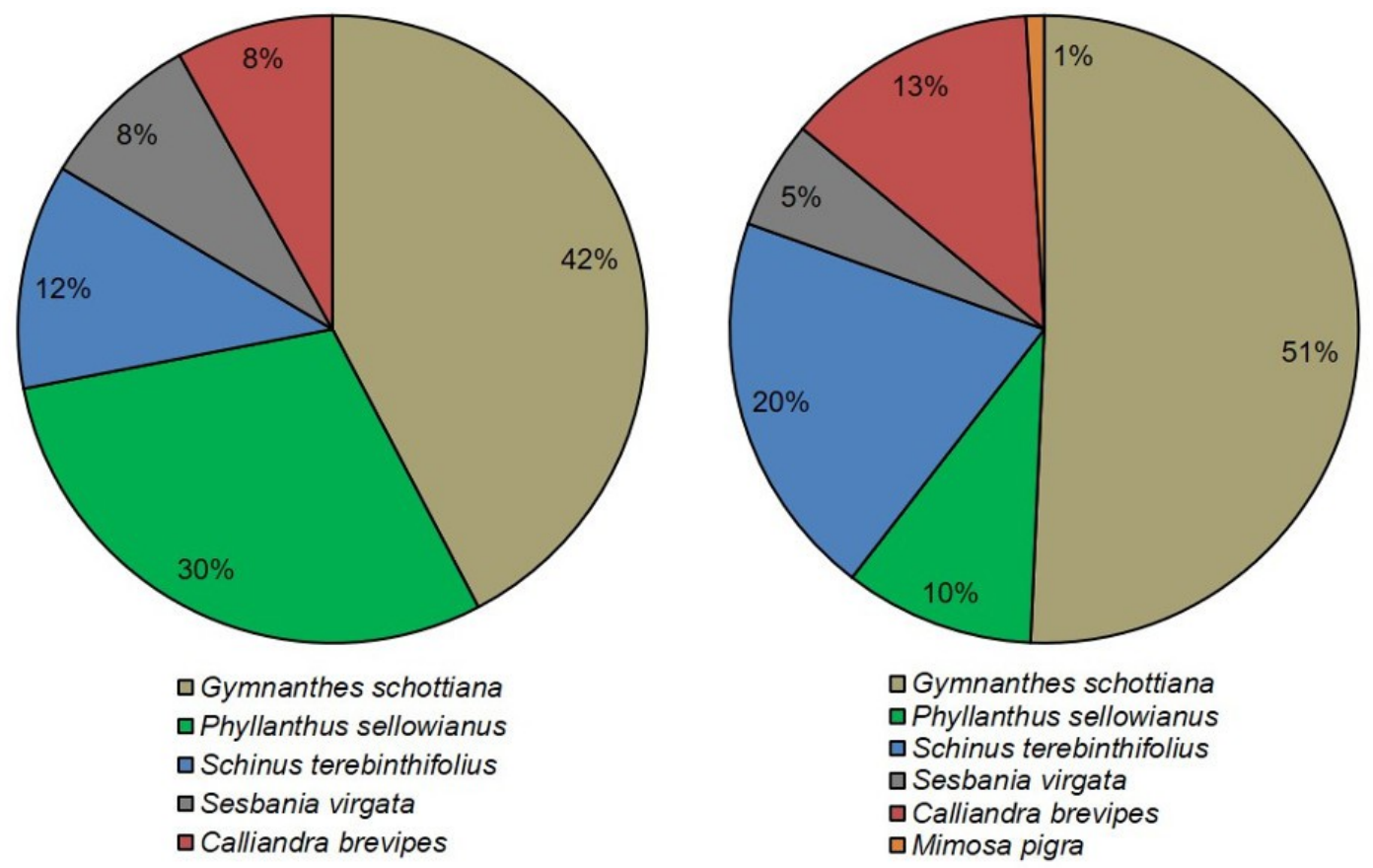

FIGURA 3 - Distribuição percentual do número total de mudas para as cinco espécies do enrocamento logo após o término da obra (à esquerda) e 24 meses após a execução da obra (à direita).

A FIGURA 4 apresenta a precipitação acumulada mensal $(\mathrm{mm})$ e a temperatura média mensal $\left({ }^{\circ} \mathrm{C}\right)$ registrada para o local nos primeiros 24 meses de implantação da obra, o que corresponde aos dois primeiros anos de desenvolvimento vegetativo das espécies implantadas. 


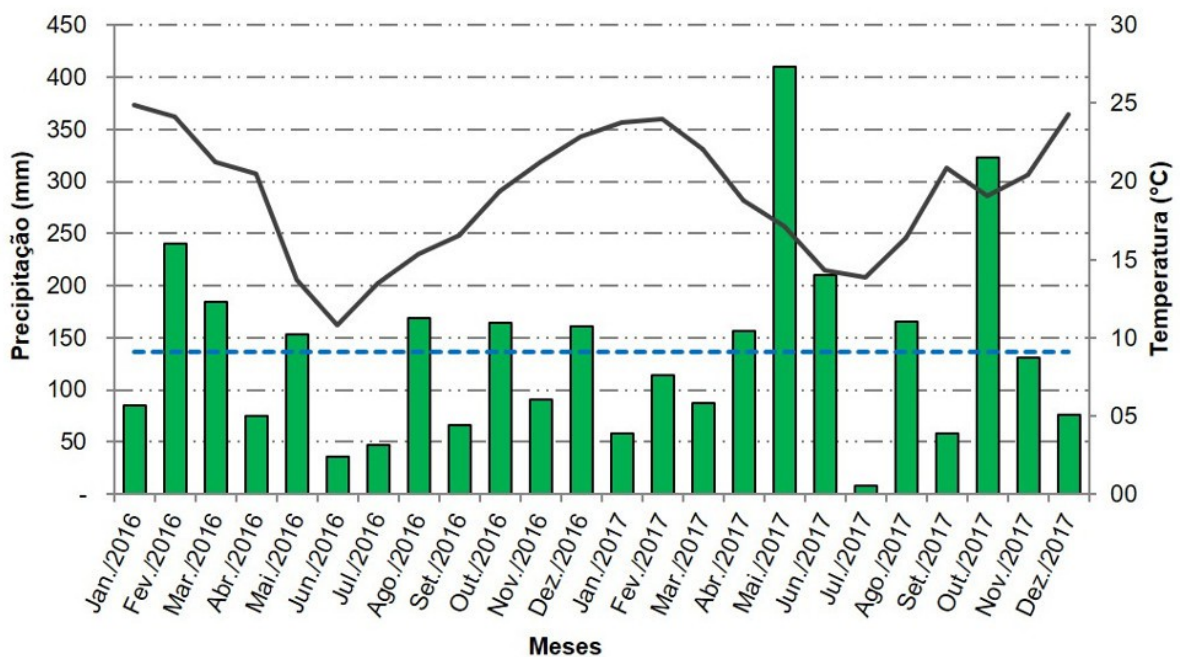

FIGURA 4 - Precipitação acumulada mensal $(\mathrm{mm})$, precipitação média mensal $(\mathrm{mm})$ e temperatura média mensal $\left({ }^{\circ} \mathrm{C}\right)$ para o primeiro ano $(2016)$ e segundo ano (2017) de desenvolvimento da vegetação.

Pode-se observar na FIGURA 4 para o ano de 2016 a ocorrência de maiores precipitações nas estações do verão e primavera com $925 \mathrm{~mm}$ acumulados e menores precipitações para as estações do outono e inverno com $546 \mathrm{~mm}$. A média de precipitação mensal para o ano de 2016 foi de $123 \mathrm{~mm}$ com total anual de 1471 $\mathrm{mm}$. Em comparação ao ano de 2016, maiores precipitações foram registradas no ano de 2017, com média mensal de $150 \mathrm{~mm}$ e total anual de $1798 \mathrm{~mm}$. A média mensal de precipitação para os anos de 2016 e 2017 foi de 136 mm.

Para o primeiro ano de desenvolvimento vegetativo, o verão de 2016 foi a estação do ano em que ocorreram as maiores precipitações acumuladas (509 mm), com destaque para os meses de fevereiro e março. Esses grandes volumes de chuva nos meses de fevereiro $(240 \mathrm{~mm})$ e março $(184 \mathrm{~mm})$ de 2016 logo nos dois primeiros meses após o término da execução da intervenção contribuíram positivamente para boas taxas de sobrevivência, assim como para um rápido crescimento e desenvolvimento de biomassa aérea para todas as espécies implantadas, conforme pode ser observado na FIGURA 5 (à esquerda).

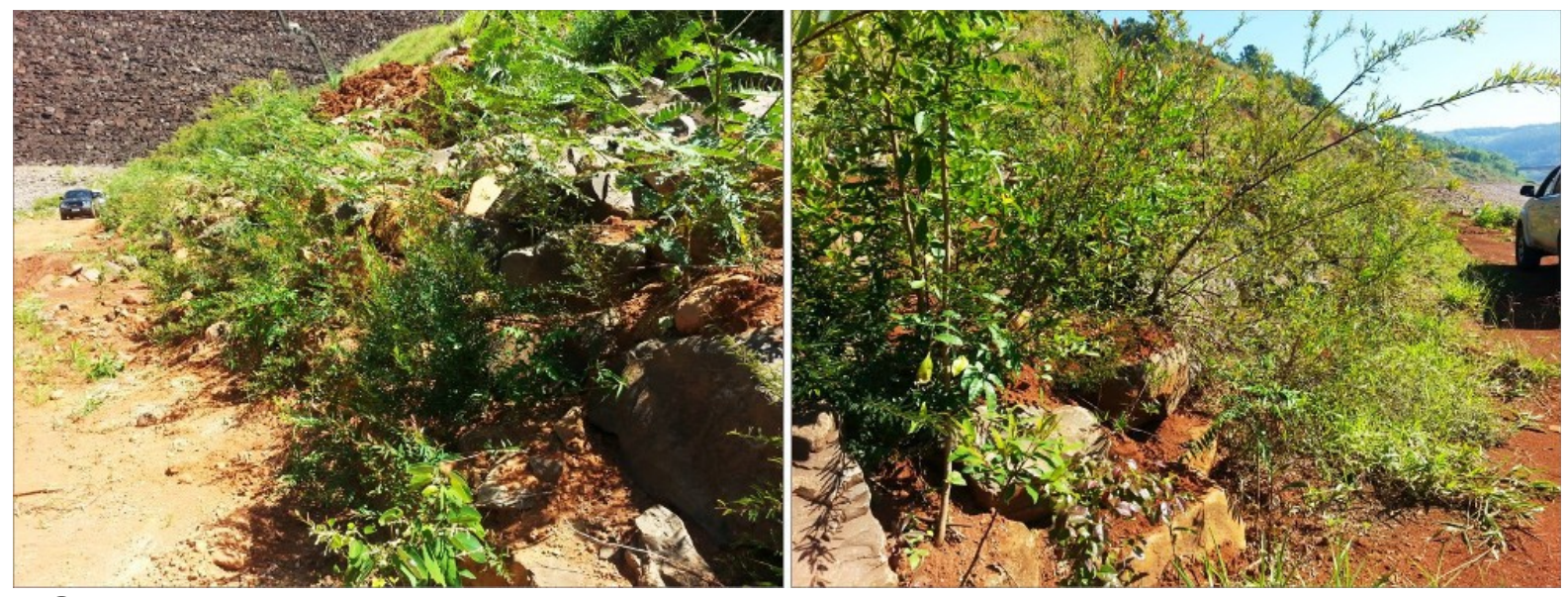

FIGURA 5 - Vista longitudinal do enrocamento vivo 2 meses após a execução da obra (à esquerda). Detalhe do desenvolvimento vegetativo das espécies arbustivas e arbóreas oito meses após a execução da obra (à direita). Fonte: Junior J. Dewes (acervo pessoal). 
Os resultados apresentados na FIGURA 5 (à direita) permitem afirmar que boa parte da superfície da estrutura encontrava-se coberta por vegetação aos oito meses após a execução da obra. A análise deste aspecto é de grande importância, uma vez que o objetivo da execução deste tipo de solução técnica também leva em consideração uma rápida e eficiente integração paisagística da estrutura, proporcionando ganhos estéticos e ambientais ao local tratado.

Dentre todas as espécies, a $S$. virgata apresentou desenvolvimento muito vigoroso de biomassa aérea aos 8 meses após implantação, adaptando-se com facilidade ao local. O crescimento de G. schottiana mostrou-se excelente, com desenvolvimento de copa bastante densa e perfilhada, contribuindo com uma boa e rápida cobertura da superfície da estrutura. $P$. sellowianus, no entanto, desenvolveu ramos mais longos com poucas folhas, dominando em relação à $G$. schottiana, $C$. brevipes e $S$. terebinthifolius, devido ao seu caráter heliófilo. As espécies $S$. terebinthifolius e C. brevipes também apresentaram bom desenvolvimento.

Rauch et al. (2014) e Kettenhuber et al. (2017) observaram um ótimo desenvolvimento da vegetação implantada em uma obra de Engenharia Natural executada em um trecho da margem esquerda do rio Pardinho, em Santa Cruz do Sul (RS). Segundo os autores, as mudas de espécies reófitas autóctones plantadas entre as pedras do enrocamento apresentaram rápido crescimento e proporcionaram cobertura superficial ao talude tratado. Isto acarretou na diminuição da velocidade do fluxo e deposição de sedimentos oriundos de montante devido ao aumento da rugosidade hidráulica conferida pelas plantas junto à margem, atestando uma alta eficiência da técnica na estabilidade e recuperação da área alterada.

As espécies arbóreas implantadas na base da estrutura apresentaram boas taxas de sobrevivência (98\%), no entanto, o desenvolvimento em altura destas plantas foi ligeiramente inferior ao impresso pelas plantas arbustivas implantadas dentro do enrocamento 8 meses após a implantação, conforme pode ser observado na FIGURA 5.

A FIGURA 6 mostra o aspecto geral do local com destaque para o desenvolvimento vegetativo das espécies arbóreas e arbustivas 24 meses após a execução do enrocamento.

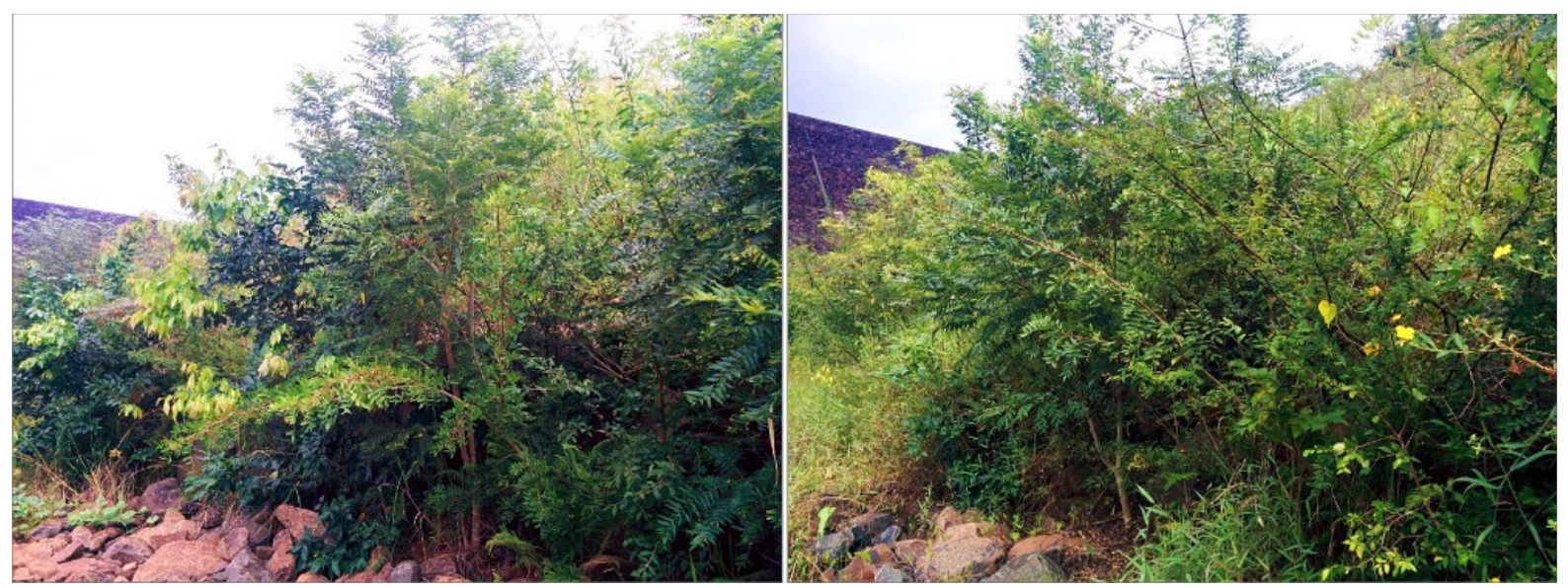

FIGURA 6 - Vista longitudinal com aspecto geral do desenvolvimento das plantas arbóreas e arbustivas 24 meses após a implantação do enrocamento. Fonte: Rita S. Sousa (acervo pessoal).

Pode-se observar que o ótimo desenvolvimento de biomassa aérea das espécies arbustivas e arbóreas proporcionou uma completa integração paisagística 
da face do enrocamento, resultando em ganhos ambientais e estéticos. A abundância de chuva e altas temperaturas durante o verão e primavera nos dois primeiros anos após a implantação da obra contribuiu para o rápido desenvolvimento das plantas e a eficiente cobertura superficial do local tratado.

De modo geral, com o desenvolvimento das plantas e o estabelecimento de competição entre as mesmas, ocorreu uma diminuição do número total de indivíduos após 2 anos de implantação da obra, conforme pode ser observado na. Os dados mostram uma redução de $30 \%$ do número total de plantas de espécies arbustivas, resultando em uma densidade de $2,5 \mathrm{un} . / \mathrm{m}^{2}$. No caso das espécies arbóreas ocorreu uma redução de $6 \%$ do número total plantado. Esta redução ocorreu naturalmente devido a uma maior demanda por nutrientes, luz e água impostas pelo desenvolvimento das plantas, sendo que as menos favorecidas e adaptadas acabaram sendo eliminadas por competição. A diminuição do número de indivíduos serve, no entanto, como indicativo da evolução e do amadurecimento da obra, conforme observado por outros autores em trabalhos de recuperação de áreas alteradas (MARCUZZO et al., 2015; RECH et al., 2015).

Com base na pode-se observar um aumento do número de indivíduos após dois anos de avaliação para a espécie $C$. brevipes, $S$. terebinthifolius e $M$. pigra. Este aumento está relacionado à alta rusticidade, boa capacidade de adaptação a áreas degradadas e à estratégia de propagação destas espécies, que produzem abundante quantidade de sementes, conforme foi constatado no local.

Esta condição não foi observada para a espécie $P$. sellowianus que apresentou uma diminuição drástica no número de indivíduos após 24 meses de implantação da obra. Para esta espécie foram observados apenas 168 indivíduos, ou seja, houve uma redução de $77 \%$ do número total inicial de indivíduos. Isto decorre do fato da espécie $P$. sellowianus possuir hábito tipicamente heliófilo, necessitando permanecer completamente exposta ao sol, condição que não ocorreu com o início da competição conferida pelas outras espécies arbustivas e arbóreas. $O$ desenvolvimento vigoroso de biomassa aérea principalmente pelas espécies $C$. brevipes, G. schottiana e pelas espécies arbóreas na base do enrocamento provocaram sombreamento excessivo, o que por sua vez provocou diminuição do desenvolvimento e a senescência e morte de muitos indivíduos de $P$. sellowianus.

Desta forma, o uso de $P$. sellowianus em enrocamento vivo combinado com outras plantas mostrou-se eficiente a curto prazo, devido ao rápido crescimento vegetativo da espécie nos primeiros meses de desenvolvimento. No entanto, a espécie pode ser facilmente dominada por meio da diminuição da exposição à radiação solar conferida por outras espécies que apresentem maior porte e copas mais densas. As espécies C. brevipes, G. schottiana, M. pigra, S. terebinthifolius e $S$. virgata apresentaram bom comportamento diante da competição imposta entre as plantas, sendo altamente indicadas para uso na técnica de enrocamento vivo para implantação em ambientes secos ou de encostas.

Após dois anos de avaliação da obra não foi constatato nenhum dano estrutural no enrocamento em função de movimentos de terra. A estrutura física permanece intacta e continua a desempenhar as funções técnicas de proteção da base da encosta para a qual foi projetada e executada. A eficiência e a estabilidade da obra tenderão a aumentar com o passar do tempo à medida que ocorrer o desenvolvimento vegetativo das plantas, principalmente da linha de espécies arbóreas implantadas na base do enrocamento.

\section{CONCLUSÃO}


O enrocamento vivo cumpre de forma eficiente a proteção mecânica da base da encosta dois anos após a intervenção, sendo que nenhum dano físico foi observado na estrutura.

O uso de plantas mostrou-se eficiente para proporcionar uma rápida integração paisagística da obra, gerando benefícios econômicos, ambientais e estéticos.

As plantas instaladas junto à estrutura encontram-se em pleno desenvolvimento vegetativo e estão a contribuir para o aumento da estabilidade da mesma através de seus sistemas radiculares e parte aérea.

Para execução de enrocamento vivo em taludes secos ou de encostas, recomenda-se especialmente o uso das espécies C. brevipes, G. schottiana, S. terebinthifolius, $S$. virgata e $M$. pigra, pois apresentaram boa rusticidade e boa capacidade de adaptação a áreas alteradas.

Apesar da diminuição do número total de indivíduos após 24 meses, a utilização de $P$. sellowianus não deve ser descartada, uma vez que a espécie apresenta excelentes taxas de desenvolvimento nos primeiros meses, sendo naturalmente substituída por outras espécies após um certo período de tempo.

\section{REFERÊNCIAS}

BRASIL, Ministério do Meio Ambiente. Caderno da região hidrográfica do Uruguai. Brasília: MMA, 2006.

CONSÓRCIO ITÁ. Itá: Memória de uma Usina. Itá: Ed. Takano, 2000.

JUSTUS, J. O. Geologia da região sul. In: MESQUITA, O. V. (Ed). Região Sul. Rio de Janeiro: IBGE, 1990.

KETTENHUBER, P. L. W.; DEWES, J. J.; SUTILI, F. J. Engenharia Natural para estabilização hidráulica do rio Pardinho em Santa Cruz do Sul - RS. Ciência \& Ambiente, v. 46/47, p. 111-130, 2017 . Disponível em: <http://w3.ufsm.br/cienciaeambiente/resenha.php?IDResenha=535>.

MARCUZZO, S. B.; ARAÚJO, M. M.; GASPARIN, E. Plantio de espécies nativas para restauração de áreas em unidades de conservação: um estudo de caso no sul do Brasil. Floresta, v. 45, n. 1, p. 129-140, 2015. Disponível em: <http://dx.doi.org/10.5380/rf.v45i1.32763>. DOI: 10.5380/rf.v45i1.32763

RAUCH, H. P.; SUTILI, F.; HÖRBINGER, S. Installation of a riparian forest by means of soil bioengineering techniques - Monitoring results from a river restoration work in southern Brazil. Open Journal of Forestry, v. 4, n. 2, p. 161-169, 2014. Disponível em: <http://dx.doi.org/10.4236/ojf.2014.42022>. DOI: 10.4236/ojf.2014.42022

RECH, C. C. C.; SILVA, A. C. da; HIGUCHI, P.; SCHIMALSKI, M. B.; PSCHEIDT, F.; SCHMIDT, A. B. et al. Avaliação da restauração florestal em uma APP degradada em Santa Catarina. Floresta e Ambiente, v. 22, n. 2, p. 194-203, 2015. Disponível em: $\quad<$ http://dx.doi.org/10.1590/2179-8087.083414>. DOI: 10.1590/21798087.083414 .

SOUSA, R. S.; MAFFRA, C. R. B.; SUTILI, F. J. Engenharia Natural para estabilização de travessia dutoviária - Caso 1. Ciência \& Ambiente, v. 46/47, p. 
131-152, 2017. Disponível em:<http://w3.ufsm.br/cienciaeambiente/resenha.php? IDResenha=536>.

SOUSA, R. S.; SUTILI, F. J. Aspectos Técnicos das Plantas utilizadas em Engenharia Natural. Ciência \& Ambiente, v. 46/47, p. 31-71, 2017. Disponível em: <http://w3.ufsm.br/cienciaeambiente/resenha.php?IDResenha=532>.

STUDER, R.; ZEH, H. Soil Bioengineering: construction type manual. 2 ed. Zurich: vdf Hochschulverlag AG an der ETH, 2014. 